\title{
Abdominoplastia com lipoaspiração e descolamento mínimo
}

\author{
Abdominoplasty with liposuction and minimal undermining
}

Jỗo Erfon Almeida

RAMOS $^{1}$

Trabalho realizado na ArtClinic, Fortaleza, CE, Brasil.

Artigo submetido pelo SGP (Sistema de Gestão de Publicações) da RBCP.

Artigo recebido: 6/1/2011 Artigo aceito: $22 / 2 / 2011$

\begin{abstract}
RESUMO
O autor descreve sua metodologia, em abdominoplastia associada à lipoaspiração, utilizando os princípios de manutenção da vascularização e da drenagem linfática do abdome. Introduz uma modificação na preservação do sistema vascular, mantendo dois triângulos de fáscia superficial lateral e a ressecção do segmento medial infraumbilical, que permite uma plicatura ampla e adequada da fáscia muscular abdominal, bem como uma pubectomia parcial (PP). Esta modificação tem sido importante para a obtenção de resultados estéticos semelhantes àqueles conseguidos com a técnica clássica, acrescidos do benefício de uma lipoaspiração ampla, em toda a extensão do abdome e flancos, melhorando o resultado final, e reduzindo a incidência de complicações.
\end{abstract}

Descritores: Abdome/cirurgia. Parede abdominal/cirurgia. Lipectomia. Cirurgia Plástica/ métodos.

\begin{abstract}
The author describes his methodology of abdominoplasty associated to liposuction of the abdomen, following the principles of sparing local blood supply and lymphatic drainage. Modifications regards to a reduced undermining of the abdominal flap, localized to the central part and wide enough to allow the rectus muscle plication. It also advocates a reduced medial resection of the infra-umbilical tissue, preserving lateral triangles of connective tissue and the perforator vessels to the flap and partial pubectomy. A single stage operation including abdominoplasty resection and liposuction has improved the aesthetic outcomes, the minimal dead space and preservation of important blood supply, has reduced the incidence of complications comparing to classic techniques of abdominoplasty.
\end{abstract}

Keywords: Abdomen/surgery. Abdominal wall/surgery. Lipectomy. Plastic surgery/methods.

\section{INTRODUÇÃO}

De 1980 a 2001, realizamos a abdominoplastia clássica $^{1,2}$, com amplo descolamento, sem lipoaspiração e com plicatura da diástase muscular ${ }^{3,4}$. O procedimento era realizado com bastante cuidado, para não comprometer a circulação do retalho abdominal e evitando, sempre, aspirar a área descolada ${ }^{5}$. Drenagem era usada por $48 \mathrm{~h}$, como na técnica clássica ${ }^{6}$, sistematicamente, mesmo assim tendo uma alta incidência de seromas. Também realizávamos, com frequência elevada, lipoaspiração secundária após 6 meses das cirurgias de abdominoplastia. A combinação de abdominoplastia com lipoaspiração do retalho abdominal era considerada como de alto risco de complicações, como, por exemplo, necrose de pele.

Desde 2001, temos realizado a abdominoplastia associada à lipoaspiração $0^{1,7}$, acrescentando um descolamento central mínimo, para permitir boa correção da diástase muscular abdominal, com boa visibilidade da fáscia muscular ${ }^{8}$ e com o cuidado de manter a circulação perfurante músculo-cutânea bem como a fáscia transversal infraumbilical lateral, importante pela circulação acessória e para a drenagem linfática. Após plicatura da fáscia muscular, inexiste "espaço morto", tornando desnecessária a utilização de drenos.

1. Cirurgião plástico, Membro Titular da Sociedade Brasileira de Cirurgia Plástica; Membro da Academia Cearense de Ciências (ACECI), Diretor da ArtClinic, Fortaleza, CE, Brasil. 
A ressecção do segmento medial infraumbilical, acrescentada por nós, é importante não só para facilitar a plicatura, bem como para reduzir a malha de tecido conjuntivo vascularizado infraumbilical, favorecendo a acomodação da mesma e os resultados estéticos.

\section{MÉTODO}

Realizamos 483 abdominoplastias no período de junho de 2001 a julho de 2010 , sendo 480 pacientes do sexo feminino e 3, do masculino, com idades variando de 24 a 61 anos.

Foram realizados os seguintes procedimentos:

- 418 abdominoplastias completas - exérese de toda a pele infraumbilical (Figura 1A);

- 35 miniabdominoplastias - exérese mínima de pele suprapública, sem a necessidade de incisão umbilical e mantendo a cicatriz resultante limitada à região pública (Figura 1B);

- 30 mid-abdominoplastias - exérese de pele mais ampla que na miniabdominoplastia, com extensão lateral ao púbis, porém menor que no abdome completo, sem incisão umbilical (Figura 1C).

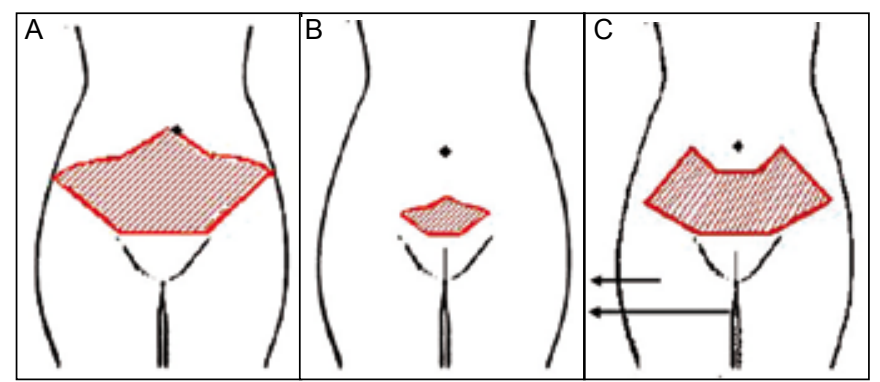

Figura 1-A: Planejamento da abdominoplastia completa; B: Planejamento da miniabdominoplastia. C: Planejamento da mid-abdominoplastia.

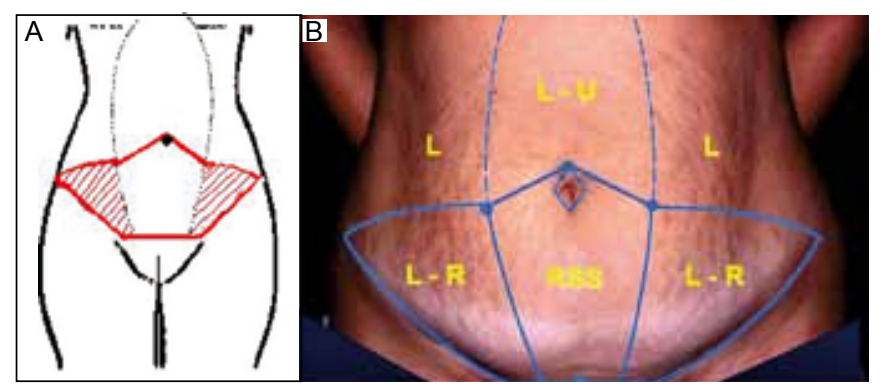

Figura 2-A: Esquema demonstrando a ressecção infraumbilical do tecido conjuntivo subcutâneo e a fáscia muscular pronta para plicatura. B: Planejamento cirúrgico: L (lipoaspiração); $L-U$

(lipoaspiração e descolamento); L-R (lipoaspiração e ressecção de pele); RSS (ressecção da pele e do tecido subcutâneo).

\section{Técnica}

Abdominoplastia completa - Os pacientes tiveram os locais de lipoaspiração demarcados, incluindo as regiões dorsais e flancos ântero-posteriores, no pré-operatório, em ortostase. Submetidos à anestesia geral. Amarcação continua com os pacientes já anestesiados, na sala de operação, em posição dorsal (Figura 2). Inicialmente marcamos o púbis e continuamos com a linha inferior, que segue o sulco abdominal inferior, nas laterais, e se continuam com a linha de incisão púbica, que é desenhada de modo a deixar um púbis de tamanho adequado, em torno de 5 a $6 \mathrm{~cm}$, sendo necessária, na maioria das vezes, ressecção de parte do púbis (pubectomia parcial). Em seguida, desenhamos as incisões umbilicais, de forma losangular. Desde o topo do umbigo desenhamos dois segmentos de retas laterais, do mesmo tamanho das linhas do púbis (Figura 2). Complementamos a marcação delimitando as linhas curvas superiores, desde a extremidade lateral destes últimos segmentos de retas até a extremidade das linhas laterais (Figura 2). Delimitamos a área de ressecção, de pele e subcutâneo, central infraumbilical (Figuras 2 e 3A), por meio de duas linhas oblíquas que partem, das extremidades laterais, dos segmentos de retas superiores, e se aproximam, confluindo até $2 \mathrm{~cm}$ do ponto central do púbis, determinando três áreas no abdome inferior: dois triângulos laterais (Figuras 2 e 3B), onde a fáscia superficial será mantida e a área central descrita acima será ressecada.

Todos os pacientes foram infiltrados com uma solução salina vasoconstrictora (soro fisiológico com adrenalina numa proporção 1:500000) para reduzir a perda sanguínea. A operação se inicia com a lipoaspiração de todo o abdome, com o mesmo rigor que obedecemos quando fazemos este método isoladamente ${ }^{9}$. A lipoaspiração sob a pele a ser ressecada é, portanto, mais rigorosa que nas outras áreas. Em seguida, retiramos a pele total dos triângulos laterais (Figura 3B), mantendo o sistema vascular ${ }^{1}$, na área em que fazemos a dissecção total da pele, atentando-se para a retirada de todos os anexos da mesma, mantendo a fáscia transversal e toda a sua vascularização de aporte (Figuras 3B e 3C), pela manutenção do tecido conjuntivo aí existente, com sua circulação íntegra, bem como o sistema linfático. Prosseguimos ressecando a parte central infraumbilical (Figuras 2 e 3A), que fica entre as duas linhas oblíquas (Figura 2), incluindo a ressecção parcial do púbis. Depois, incisamos o umbigo e continuamos o descolamento subcutâneo supraumbilical, com a largura suficiente para a plicatura, de acordo com cada caso (Figura 3D). Iniciamos a plicatura para tratamento da diástase muscular dos retos abdominais com mononylon 0 (zero) duplo, com pontos separados. A fáscia transversal lateral infraumbilical preservada é, automaticamente, aproximada, quando da plicatura 
muscular. Se necessário, plicamos a fáscia superficial e o tecido conjuntivo abdominal inferior lateral, mantendo a vascularização acessória (vasos epigástricos inferiores superficiais e vasos cincunflexos ilíacos superficiais) e os vasos linfáticos, desta área (Figura 3E).

Com o paciente fletido, iniciamos o fechamento da ferida com cinco pontos principais de mononylon 0 (zero), na região púbica, e continuamos a sutura com mononylon $3 \mathrm{x} 0$ incolor ou monocryl $3 \mathrm{x} 0$ e concluímos com Dermabond (Figura $3 \mathrm{~F}$ ). Ressuturamos o umbigo com mononylon $4 \mathrm{x} 0$ (Figura 4).
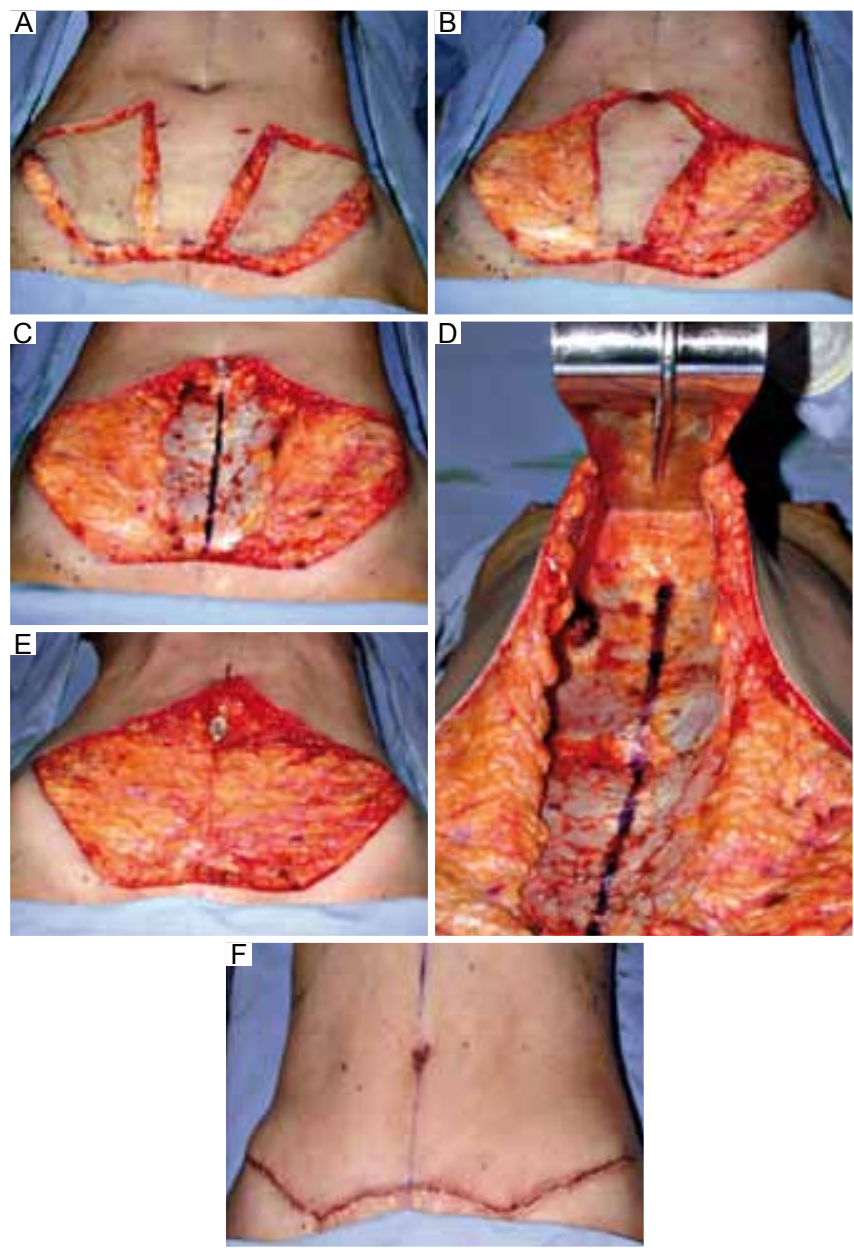

Figura 3 - A: Começo da cirurgia com lipoaspiração das áreas marcadas e incisão dos retalhos laterais do abdome. B: Exérese de pele total nos retalhos laterais do abdome, mantendo a fáscia superficial intacta. C: Ressecção da área central infraumbilical, expondo a fáscia muscular e preservação da fáscia superficial nas áreas laterais. D: Descolamento do túnel para plicatura do umbigo até o apêndice xifoide. $\boldsymbol{E}$ : Conclusão da plicatura preservando todo o sistema linfático e a vascularização. F: Resultado final, com bom delineamento corporal.
$\mathrm{Na}$ miniabdominoplastia (Figura 5) e na mid-abdominoplastia (Figura 6), utilizamos a mesma técnica, observando menos ressecção de pele, de acordo com cada caso (Figuras 1B, 1C, 6 e 7). Não colocamos drenos. O curativo é forrado com gazes acolchoadas e o uso de cinta elástica.
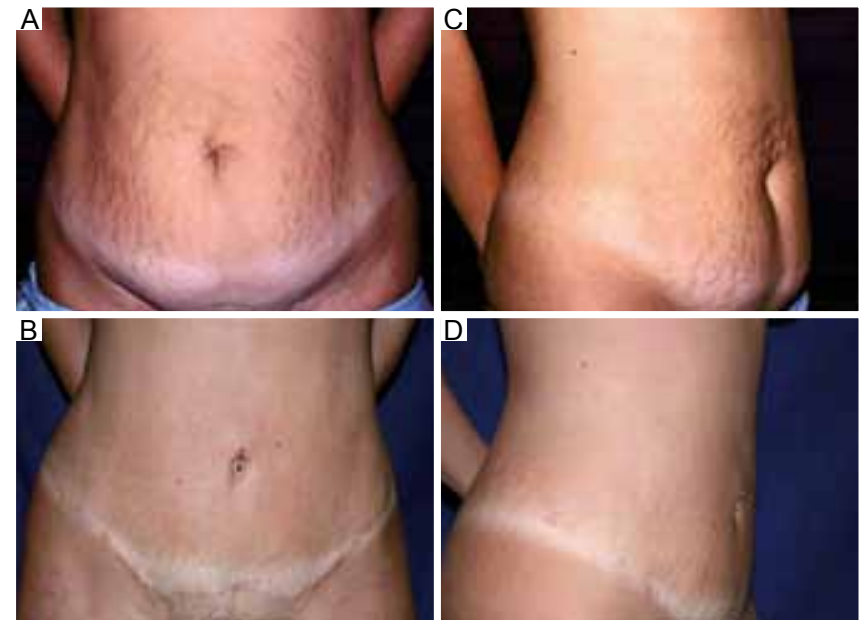

Figura 4-A e C: Pré-operatório de abdominoplastia completa. $\boldsymbol{B}$ e D: Pós-operatório de 6 meses.
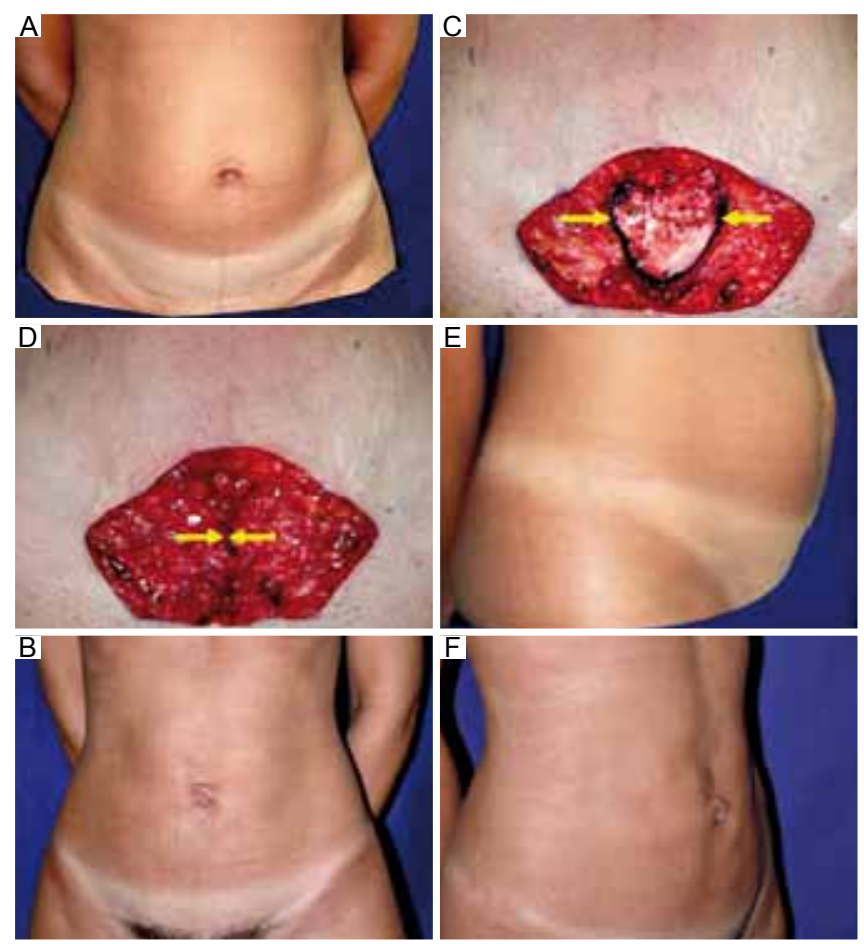

Figura 5-A, C, D e E: Pré e transoperatório de miniabdominoplastia. $\boldsymbol{B}$ e $\boldsymbol{F}$ : Pós-operatório de 6 meses. 

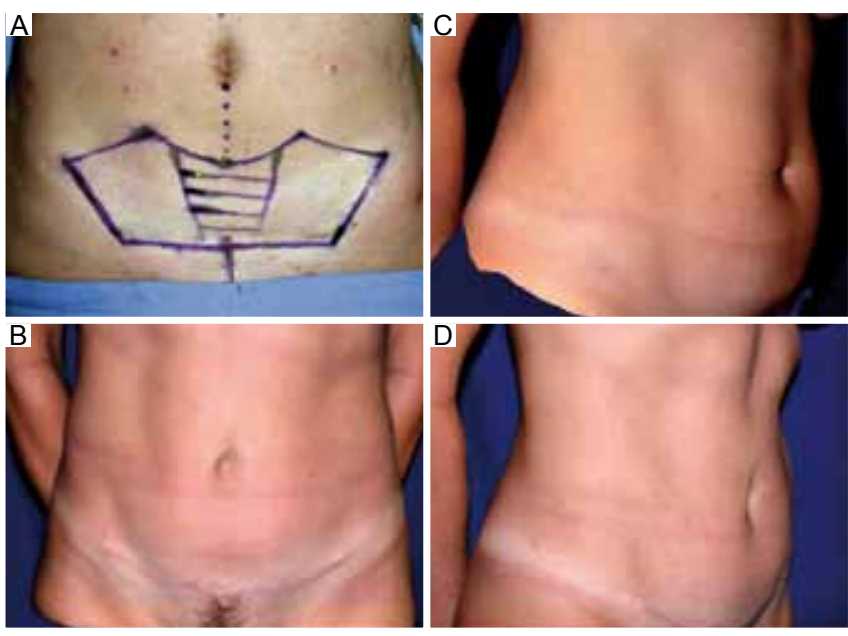

Figura 6-A e C: Pré-operatório. B e D: Pós-operatório de 6 meses
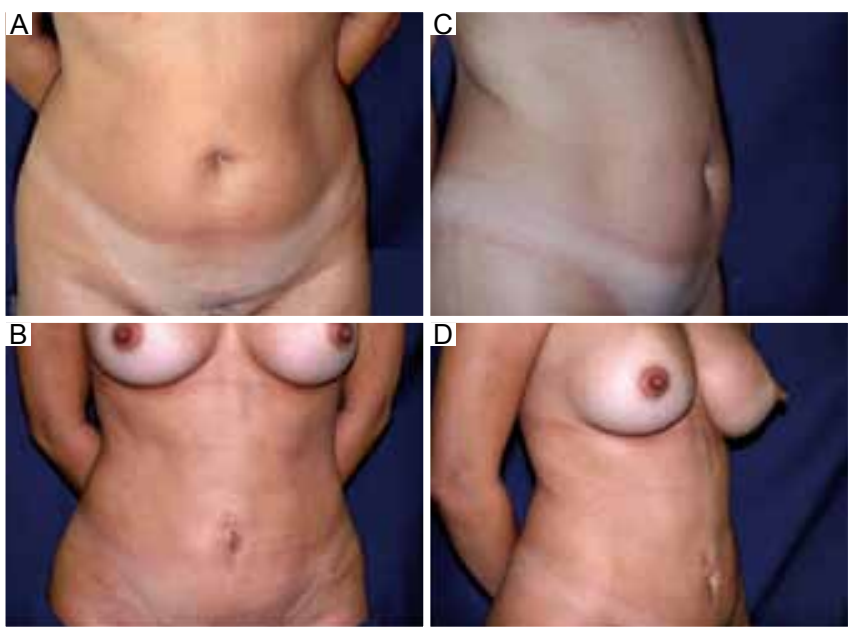

Figura 7-A e C: Pré-operatório de mid-abdominoplastia. B e D: Pós-operatório de 6 meses.

\section{RESULTADOS}

A associação da lipoaspiração à abdominoplastia ${ }^{1,9}$, com descolamento central mínimo, ressecção do segmento medial infraumbilical e pubectomia parcial melhorou os resultados estéticos quando comparados à técnica clássica por nós, utilizada antes deste procedimento. O número de complicações também se tornou quase inexistente, principalmente a que mais tínhamos (seromas), quando comparado às observadas com a técnica utilizada anteriormente.

O índice de satisfação do paciente foi altíssimo, em torno de $98 \%$. Seromas, epiteliose e deiscência de ferida não foram mais observados após introdução da técnica. Além disso, o índice de reintervenção, que era muito alto com a técnica clássica, tornou-se baixíssimo, em torno de 4\% (lipoaspiração após 6 meses de pós-operatório). As únicas complicações que tivemos com o empregi da técnica atual foram: um caso de hematoma, drenado, que necessitou de lipoaspiração secundária, com bom resultado final.

No início da experiência, nos dez primeiros pacientes, tivemos 2 (dois) casos em que exageramos na lipoaspiração supraumbilical e tivemos um pouco de flacidez de pele, nesta área.

\section{DISCUSSÃO}

Faz-se importante, na avaliação pré-operatória do paciente candidato a uma abdominoplastia, o enquadramento adequado dentro de uma das opções que oferecemos para a correção cirúrgica das deformidades estéticas do abdome (Figura 1). São importantes nesta avaliação: tipo de pele e sua textura, adiposidades localizadas e generalizadas, tônus muscular, idade dos pacientes, capacidade pulmonar, bem como avaliação do sistema vascular periférico, além dos fatores de avaliação inerentes às cirurgias plásticas em geral.

Diferentemente da abdominoplastia completa e da miniabdominoplastia, introduzimos os termos: mid-abdominoplastia e pubectomia parcial. Denominamos de mid-abdominoplastia a técnica empregada os casos que necessitam ressecção ampla da pele, mas é impossível estendê-la até a região umbilical, visto que a pele supraumbilical é insuficiente para refazer todo o abdome, sem necessidade de incisão periumbilical, com ou sem o descolamento do umbigo (Figuras 1C, 6, 7). Definimos pubectomia parcial a ressecção transversal de parte do púbis que evita cicatrizes elevadas nesta área, independente de pontos de fixação, já dando um delineamento adequado ao tamanho do púbis (Figura 5).

A recomendação de manter o sistema vascular fechado ${ }^{1}$, sem os amplos descolamentos de pele que se fazia, permite associar esta cirurgia a uma lipoaspiração extensa, sem as limitações antes necessárias, pela redução do aporte vascular ao retalho cutâneo, realmente representa um passo histórico, na evolução da técnica da abdominoplastia.

A ressecção, por nós realizada, da parte central do tecido conjuntivo subdérmico, sem prejuízo da sua vascularização ${ }^{8}$, bem como pequeno descolamento supraumbilical, permite, adicionalmente, uma visualização direta da fáscia muscular abdominal, favorecendo uma plicatura segura e correta, sem o risco de permanecer com o ponto só no tecido conjuntivo ou adentrar à cavidade abdominal, em abdomes com grandes diástases ou atrofia muscular significativa, com risco de prender uma alça intestinal, que é uma complicação muito grave. Contudo, acreditamos que contribuímos no sentido de minimizar o acúmulo de tecido conjuntivo subdérmico, sem prejuízo da vascularização e permitindo a visualização da fáscia muscular abdominal, conseguindo melhorar os resultados estéticos (Figura 4). 
Graf et al. ${ }^{10}$, em 2006, demonstraram, com o uso de Doppler, que a abdominoplastia com descolamento reduzido e preservação dos vasos perfurantes músculo-cutâneos reduz as complicações, como necroses e seromas.

Observamos, também, maior satisfação por parte dos pacientes, visto que ficamos com uma liberdade maior em relação à lipoaspiração, não só do retalho abdominal, como das regiões dorso-flanco-ilíacas, podendo-se delinear muito melhor a cintura, melhorando o resultado estético como um todo.

A ressecção central deste tecido, de pele e subcutâneo, não traz nenhum prejuízo àcirculação do retalho abdominal, que é oriunda das laterais e dos vasos perfurantes músculocutâneos ${ }^{7}$ e através de arcos anastomóticos entre os vasos epigástricos inferiores (superficiais e profundos) e os vasos cincunflexos-ilíacos (superficiais e profundos) e evita o acúmulo do mesmo após a plicatura da parte inferior do abdome. Este procedimento, associado à pubectomia parcial e ao descolamento mínimo supraumbilical, é o ponto central da nossa contribuição ${ }^{8}$. Conseguimos minimizar as complicações, com esta conduta, mormente do seroma, nossa principal complicação e que, na maioria das vezes, levava a uma reintervenção, frequentemente uma lipoaspiração secundária para correção das irregularidades deixadas ${ }^{8,11}$. Acreditamos que a redução, drástica, de lipoaspiração secundária deve-se a dois fatores: a) possibilidade de lipoaspiração ampla do retalho abdominal; b) inexistência de seromas.

\section{CONCLUSÃO}

Acreditamos que a ressecção do segmento medial infraumbilical, como descrito por nós, com uma boa visualização da fáscia muscular abdominal, sem prejuízo da circulação que é completamente mantida, quando associamos a lipoaspiração à abdominoplastia, permite uma plicatura segura dos músculos reto abdominais, sem os riscos por nós descritos neste trabalho, bem como favorece o delineamento estético final da cirurgia.
A pubectomia parcial garante uma cicatriz resultante mantida, adequadamente, dentro de um nível agradável e satisfatório, em relação à altura final do púbis.

Concluímos que a utilização da lipoaspiração associada à abdominoplastia ${ }^{1,7,9}$, com descolamento mínimo e acrescida da ressecção medial infraumbilical e da pubectomia parcial, permite a obtenção de resultados estéticos mais favoráveis, levando à melhor delineação do contorno corporal da paciente, bem como reduzindo as complicações da abdominoplastia clássica, tais como seromas, necroses e alta incidência de lipoaspirações secundárias.

\section{REFERÊNCIAS}

1. Avelar JM. Uma nova técnica de abdominoplastia: sistema vascular fechado de retalho subdérmico dobrado sobre si,combinado com lipoaspiração. Rev Bras Cir. 1999;6:3-20.

2. Sinder R. Cirurgia plástica do abdome. Rio de Janeiro: Ed. Ramil Sinder, 1979

3. Pitanguy I. Abdominal lipectomy: an approach to it through an analysis of 300 consecutive cases. Plast Recosntr Surg. 1967;40(4):384-91.

4. Uebel CO. Cirurgia do abdome associada à lipoescultura. In: Tourniex $\mathrm{AAB}$ ed. Atualização em Cirurgia Plástica Estética. São Paulo:Robe Editorial; 1994. p.483-9.

5. Matarasso A. Liposuction as an adjunct to a full abdominoplasty revisited. Plast Reconstr Surg. 2000;106(5):1197-205.

6. Callia WEP. Contribuição para o estudo da correção cirúrgica do abdome pêndulo e globoso: técnica original [Tese de doutorado]. São Paulo: Faculdade de Medicina da Universidade de São Paulo; 1965.

7. Saldanha OR, Pinto EB, Matos WN Jr, Lucon RL, Magalhães F, Bello EM. Lipoabdominoplasty without undermining. Aesthet Surg J. 2001;21(6):518-26.

8. Erfon J. Abdominoplasty through a closed vascular system associated to liposuction: Avelar's technique. In: Avelar JM, ed. Abdominoplasty. São Paulo. Hipócrates,2002. p.299-307.

9. Illouz YG. Une nouvelle technique pour les lipodystrophies localiseés. Rev Chir Esthet Franc. 1980;6(9).

10. Graf R, Araujo LR, Rippel R, Neto LG, Pace DT, Cruz GA. Lipoabdominoplasty: liposuction with reduced undermining and traditional abdominal skin flap resection. Aesthetic Plast Surg., 2006;30(1):1-8.

11. Baroudi R, Ferreira CA. Seroma: how to avoid it and how to treat it. Aesthet Surg J. 1998;18(6):439-41.

\section{Correspondência para:}

